\title{
\#RHODESMUSTFALL: USING SOCIAL MEDIA TO "DECOLONISE" LEARNING SPACES FOR SOUTH AFRICAN HIGHER EDUCATION INSTITUTIONS: A CULTURAL HISTORICAL ACTIVITY THEORY APPROACH
}

\author{
S. Francis* \\ e-mail: sieraaj.francis@uct.ac.za
}

\author{
J. Hardman* \\ e-mail: joanne.hardman@uct.ac.za
}

*School of Education

University of Cape Town

Cape Town, South Africa

\section{ABSTRACT}

Since the end of 2015, South African universities have been the stage of ongoing student protests that seek to shift the status quo of Higher Education Institutes through calls to decolonise the curriculum and enable free access to HEls for all. One tool that students have increasingly turned to, to voice their opinions has been social media. In this article we argue that one can use Cultural Historical Activity Theory to understand how the activity systems of the traditional academy are shifting the wake of social media, with traditional power relations becoming more porous as students' voices gain an audience. By tracing the historical development of CHAT, we show how $4^{\text {th }}$ generation CHAT enables us to analyse potential power shifts in HEls brought about through the use of social media.

Keywords: decolonising the curriculum Higher Education, cultural historical activity theory

\section{INTRODUCTION}

2015 was rife with controversy in South Africa, but it was an exciting time as important conversations around access to higher education, the inclusivity of South African universities and decolonisation became part of public conversation (Kamanzi 2015; Hlophe 2015; Masondo 2015). This movement became known under the hashtag of \#Rhodesmustfall, indicating the need to decolonise academic spaces felt by those in the movement. In subsequent years this movement has transformed into \#feesmustfall, indicating the students' driving motive to gain access to institutes of higher learning. These discussions were accompanied by days of massive student demonstrations across South Africa. Social media played an important role in not only organising the protests but also allowing information around these important issues to be shared 
between students and the general public. With knowledge production and learning activities often overlooked during activism (Choudry and Kapoor 2010), we look at the potential for Higher Education Institutions to adopt social media as learning spaces and knowledge production spaces that are inclusive, egalitarian and decolonised. In this article, we explore how Cultural Historical Activity Theory can be used as a framework to explore the potential for social media to facilitate the decolonisation of South African universities.

\section{BACKGROUND}

On 9 March 2015, Chumani Maxwele, a UCT student, flung faeces at statue of Cecil John Rhodes on the University of Cape Town's upper campus (Verbaan 2015). This was part of a protest of about a dozen students at the university with a call to decolonize the university and stop white imperialism (Verbaan 2015). The movement that followed, the Rhodes Must Fall (RMF) movement, has been making headlines ever since for their protests across South Africa which have multiplied in numbers and intensity. This movement criticises universities for not transforming themselves and breaking ties with their colonial pasts (Hlophe 2015; Kamanzi 2015). The movement also aimed to give voice to the voiceless students who feel marginalized, alienated and underrepresented by the universities' curricula and historic cultural and colonial practices (Hlophe 2015). Colonial artwork has been attacked by students and a call to rework the curriculum has also been made (Kamanzi 2015). There are continuous discussions "about how these artefacts and names reflect the continued exclusion of different epistemologies of thought, different races, classes and gender based oppressions” (Kamanzi 2015). Riding on the coattails of the RMF movement came the Fees Must Fall (FMF) movement through which students demanded the abolishment of tuition fees at South African universities. If South African universities do not improve access for students from previously disadvantaged communities (access not just in admission, but in tuition and an accessible curriculum), then South African universities will not be transformative in their education practices but will instead perpetuate the socioeconomic inequalities that exist in our societies (Kamanzi 2015).

\section{PROBLEM}

The impetus for this article derives from an interest in how the Rhodes Must Fall movement successfully leveraged social networks such as Twitter and Facebook to organize their protests and raise awareness of the issues that they are protesting against (Masondo 2015). The creation of a Facebook group and the twitter hashtag “\#RhodesMustFall” was used to send information to the members and prospective members (Masondo 2015). We see in this use of social media the potential to disrupt traditional power relations in the academy, giving students a voice they 
previously did not have. Outside of the communication channels set up by the group on social media, there were also news articles released on social media by the general media that reported on the protests and the issues around them. Social Media users also used their accounts to provide eye-witness reports and construct opinion pieces about the protests and their related issues. While these posts became a space for controversy and conflict, they also allowed for social media users to discuss, debate, construct their knowledge around the related issues and challenge their understanding of these issues. Social media provided a platform to the general public, students and higher education institutions to have access to the information about the organization of the protests as well as to get an understand of the affective and intellectual concerns held by students and the general public.

The use of social media by activists has been observed and studied in many contexts, globally. Across the world students have used social media to organize protests and distribute messages about various socio-political and socioeconomic issues. These contexts vary from Western, first world contexts such as Occupy Wall street (Gerbaudo 2012), the "indignados” movement in Spain (Gerbaudo 2012) and "Unibrennt" in Austria (Maireder and Schwarzenegger 2012) to third world contexts like Chile (Valenzuela 2013) and Egypt (Lim 2012; Gerbaudo 2012). Through these studies, we have learned how students use social media to communicate and organize themselves and how social media can provide a way of mobilizing disparate groups without real leaders or “soft leaders” (Gerbaudo 2012; Maireder and Schwarzenegger 2012).

While the organization and social issues involved in social movements have been well researched, "the dynamics, politics, and richness of knowledge production within social movements and activist contexts are often overlooked in scholarly literature, and sometimes even in the movements them-selves" (Choudry and Kapoor 2010, 1). They state quite eloquently:

\footnotetext{
"As we argue elsewhere (Choudry, 2007, 2008; Kapoor, 2009a), the voices, ideas, perspectives and theories produced by those engaged in social struggles are often ignored, rendered invisible, or overwritten with accounts by professionalized or academic experts. In the realm of academic knowledge production, original, single authorship is valued, which inadvertently contributes to a tendency to fail to acknowledge the intellectual contributions of activism, or to recognize the lineages of ideas and theories that have been forged outside of academe, often incrementally, collectively, and informally. That said, we do not intend to imply that these various epistemologies of knowledge (academic and activist) and processes of knowledge production and learning (formal, nonformal, and informal) necessarily exist in completely separate universes.” (Choudry and Kapoor 2010, 2).
}

In this article, therefore, we aim to explore how social media was used to aid the processes of 
knowledge production and learning during the Rhodes must fall movement. Henk Eijkman describes social media and other Web 2.0 as egalitarian transcultural contact zones which enables us "to create post-colonial learning spaces as egalitarian transcultural contact zones" (Eijkman 2008, 630). This means that social media may provide learning spaces that are more inclusive and representative of the both universities' academic and administrative staff and its students, and it might allow an opportunity for marginalized voices to be heard and for students to feel less alienated. Understanding if and how social media was Incorporated to provide inclusive conversations and learning around decolonisation, the issues related to the protests, can allow universities with broader and deeper perspectives around how we can leverage these spaces of decolonised teaching spaces. This might be an important step the decolonisation and transformation of our universities.

\section{CULTURAL HISTORICAL ACTIVITY THEORY}

Cultural Historically activity theory was founded on Lev Vygotsky's theory of learning, where he described human learning as the process of achieving higher cognitive functions using cultural tools through a process called mediation (Hardman and Amory 2015). Subjects can perform lower cognitive functions and act on an object without any mediation, because such lower cognitive functions are innate (Hardman and Amory 2015). However, higher order functions need to be mediated in order for the subject to successfully achieve their object (Hardman and Amory 2015) (see Figure 1). Vygotsky proposed that mediation was achieved through the use of cultural tools, such as language, and allowed the subject to develop higher cognitive functions. Vygotsky’s proposed description learning meant that learning was not an individual process, but was socially culturally situated.

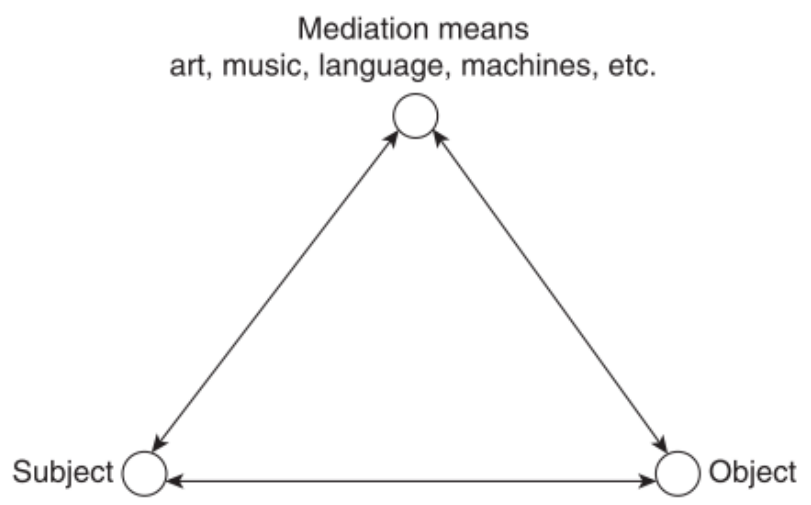

Figure 1: Vygotsky's Human Learning through mediation (Hardman and Amory 2015)

\section{SECOND GENERATION ACTIVITY THEORY}

The most notable Psychologist to further develop Vygotsky’s theory of learning is Aleksei 
Leontiev, whose work indicated that Vygotsky's theory of learning could not account for activities that involved collective action (Hardman and Amory 2015). Leontiev explained the distinction between individual action and collective activity by use of his famous example of the "primeval collective hunt" (Hardman and Amory 2015, 7). In this example, a group of hunters split themselves into two groups while hunting. Each group had their own set of actions. One group would beat the bush to scare the game in the opposite direction, while the other group would wait in the direction of the running game in order to try and catch them (McMichael 1999). The actions of the first group seem senseless with regard to the object (motive) of hunting for food, but when analysing the activity of the first group in the collective activity of hunting one gains a better understanding of how their actions lead them towards their object (McMichael 1999). Leontiev went on to expand on Vygotsky's model to include this division of labour (Hardman and Amory 2015). He placed a hierarchical structure of activity in the centre of the model (Hardman and Amory 2015) (see Figure 2). At the lowest level of the hierarchy was the automatic operations that subjects performed with the tools under thee given conditions. The middle/second layer of the hierarchy was the actions that the individual performed to reach that individual's goal (Hardman and Amory 2015). Finally, at the top layer was the collective activity that involved all the individual actions towards the collective activity’s motive/object (Hardman and Amory 2015).

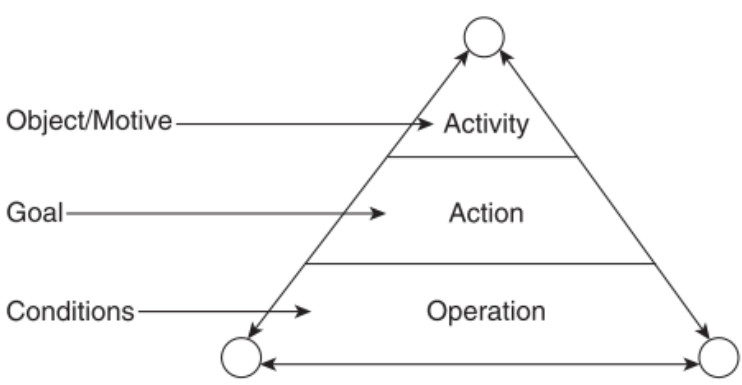

Figure 2: Leontiev's three-sage model of activity (Hardman and Amory 2015)

\section{THIRD GENERATION ACTIVITY THEORY}

While Leontiev's inclusion of the division of labour developed Vygotsky's essentially individualistic model of psychological functioning, it couldn't be used to explain the role of context and the surrounding community in the process of transformation from individual action to collective activity and exactly how the division of labour impact individual action in collective activity (Hardman 2008). Yrjö Engeström further developed Vygotsky and Leontiev's work to account for the lack of contextual understanding presented in their models 
(Hardman 2010). In Figure 3 (Hardman and Amory 2015), we see how Engeström used Vygotsky's model as the apex of his triangular system where the subject acts on the object to transform it and the subject's actions is mediated by some cultural tool. Engeström included Leontiev's concept of division of labour, but also included rules and the community as part of the model (Hardman 2008). The bottom left inner triangle shows how rules mediate the interactions between the subject and the community and in the bottom right of the triangle we see how the division of labour mediates between the community and the object. In Figure 3, Engeström has thus provided the basic unit of CHAT analysis, an activity system, which situates the activity within the context of the power structures, rules and community that is in the background of the activity (Hardman and Amory 2015). Thus, illustrating Leontiev's suggestion that activities need to be understood within their socio-cultural contexts and cannot be fully understood through observations of individual action or collective activity alone (Hardman and Amory 2015).

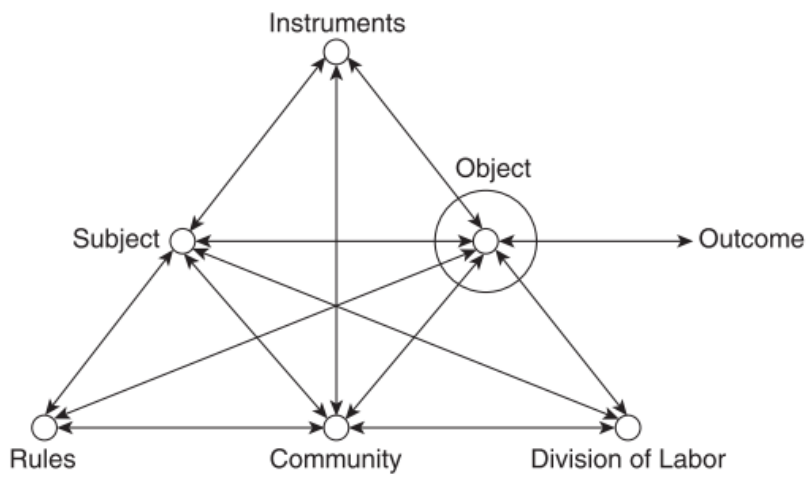

Figure 3: Engeström's conceptualization of an activity system (Hardman and Amory 2015)

This model is further developed into Figure 4 (Engeström 2001), where Engeström proposed that "a collective, artefact-mediated and object-oriented activity system, seen in its network relations to other activity systems, is taken as the prime unit of analysis” (Engeström 2001, 137). This means that the model now includes at least two activity systems with a shared object as the prime unit of analysis. This change came in response to a number of factors. Firstly, the idea that internal contradictions, or double binds, within activity systems drive transformation and change within that activity system meaning that comparing two activity systems working on the same object illuminated the contradictions between and within these activity systems (Engeström 2001). Secondly, the single activity system model is insensitive to cultural diversity and therefore, the model had to be adapted to be able to account for and represent multiple perspectives, traditions and interests (Engeström 2001). While multivoicedness is a source of conflict, it also drives innovation, demanding actions and negotiations and having multiple 
activity systems connected together in network multiplies multivoicedness (Engeström 2001). This model with at least two activity systems working on a shared object as its prime unit is referred to as Third Generation Activity Theory (3GAT).

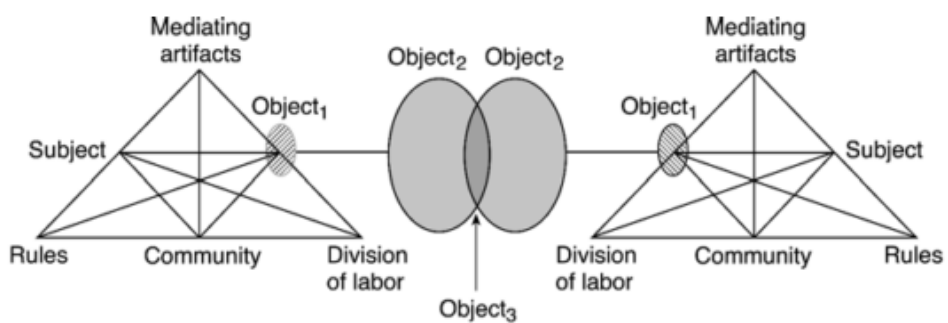

Figure 4: Two interacting systems as a minimum model for third generation activity theory (Engeström 2001)

\section{FOURTH GENERATION ACTIVITY THEORY}

Following the rise of the network society and knowledge society as described by Manuel Castells, activity theory is being reshaped again towards a Fourth Generation Activity Theory (Spinuzzi 2014). This is to accommodate the new types of collaborative activities that technological advances have enable, where collaboration happens not only within activity systems and within activity networks, but also across multiple networks of activity systems (Spinuzzi 2014). This means that no changes are made to Engeström's model of activity theory, however, new concepts and models had to be introduced to describe the way collaborators come together across networks of activity systems.

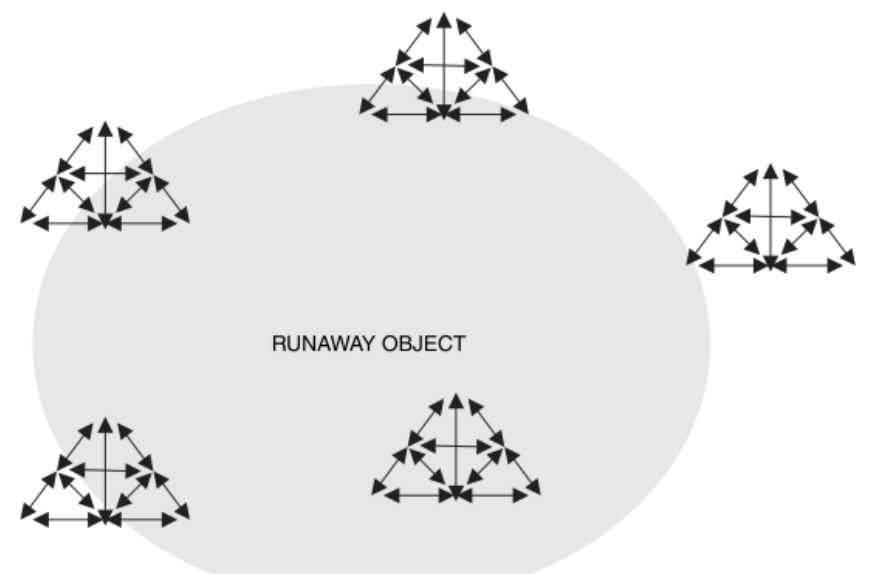

Figure 5: Large Runaway Object and Activity Systems (Engeström 2009)

The first concept is the runaway object which is usually an overarching, large, global objective that many activity networks are situated within as per Figure 5 (Engeström 2009). Even though these types of objects are usually contested and receive lots of opposition, they can also be very 
emancipatory and can open up new possibilities of development (Engeström 2009). Spinuzzi states that "the more activities are brought to bear on an object, the more fragmented, fractional, and contested it becomes" (Spinuzzi 2011). Therefore, the objects are always shifting and changing and therefore, the activity systems themselves will change as they are objectorientated (Spinuzzi 2011).

The second new concept called "knotworking" was introduced to describe the way subject collaborates across different activity systems. The term "knotworking" refers to how threads from different activity systems tie together temporarily and then untie again once the need for collaboration does not exist anymore (Kangasoja 2002). This is opposed to networks where the link between systems are more robust, defined and permanent. In "knotworking", there is no central individual, organization or authority and the collaboration takes place without predetermined rules (Kangasoja 2002; Engeström 2006).

The third concept introduced was mycorrhizae, which are the subjects or actors in large runaway objects (Engeström 2006). In Biology, mycorrhizae are symbiotic relationships that from between fungi and plants (Engeström 2006). The fungus cannot provide food for itself and has to rely on the environment for nutrients (Engeström 2006). The plant, on the other hand, produces its own food but its roots aren't as effective at retrieving water from the soils (Engeström 2006). The relationship between fungus and plants exists when the fungus breaks into the root of the plant to retrieve food from the plants roots (Engeström 2006). In return, the fungus, which has a much bigger surface area and is therefore much better equipped to retrieve water from the soil, provides the plant with water by giving water to the plants roots (Engeström 2006). This combination of fungus and plant is called "mycorrhizae" or fungal roots. From these roots, both plants and mushrooms grow, which are visible, vertical, reproductive organisms as opposed to the invisible underground horizontal fungal root structures (Engeström 2006). Engeström uses the biological concept of mycorrhizae as a metaphoric description of the new types of connections that are forming between people and organizations which are the actors in activity system (Engeström 2006). If we use this metaphor, we can conceive of the mushrooms and plants as the informal and formal bodies and vertical structures of people and institutions and the mycorrhizae beneath the ground as the informal and formal connections between them (Engeström 2006). Studying these mycorrhizal connections are difficult because these connections are unbounded and invisible and therefore are difficult to contain (Engeström 2006). However, the visible structures are still agents in the activity systems that they occupy and understanding those activity systems are crucial to understand these knotworking mycorrhizae (Engeström 2006).

These new concepts that allow us to study more collective and collaborative work across 
activity systems is referred to as Fourth Generation Activity Theory (4GAT) (Spinuzzi 2014).

\section{FRAMING THE RMF MOVEMENT AS AN ACTIVITY THEORY PROBLEM}

\section{Learning on Social Media during RMF as a Technology-Mediated Activity System}

To apply 3GAT to our learning problem, viz. the use of social media to disrupt division of labour and give voice to students, we first need a theory that explains the learning that takes place when learning with technology. In 2005, Sharples, Taylor and Vavoula set out to "to offer an initial framework for theorising about mobile learning, to complement theories of infant, classroom, workplace and informal learning” (Sharples et al. 2005, 1). Their goal was to distinguish mobile learning from traditional learning. The theory of mobile learning needed to consider the fact that the learners are mobile; the fact that a considerable amount of learning takes place outside of the classroom; they had to consider what are the contemporary successful practices that enable successful learning and they had to consider the fact that learning with personal and shared technology is a ubiquitous process (Sharples et al. 2005). The contemporary successful practices that enabled successful learning were learner centred, knowledge centred, assessment centred and community centred (Sharples et al. 2005). These factors of the successful practices, except for assessment-centeredness, are all afforded through social media discussions, were social media users construct knowledge through their interactions with others in their online communities.

Sharples et al. concluded that there were certain aspects of learning with mobile technology that distinguished it from traditional learning (Sharples et al. 2005). Firstly, they found that the learner, rather than the technology was mobile and that users were “opportunistically appropriating” all sorts of technologies as they move from context to context (Sharples et al. 2005, 4). Secondly, they found that "learning is interwoven with other activities as part of everyday life”, which meant that learning couldn't be separated from other daily activities, such as social conversations, watching television, reading, etc., and these activities could all be resources for learning (Sharples et al. 2005). Thirdly, they found that learning can help students discover and realise their goals, which could be determined by fulfilling a curriculum, determined by their needs, or new goals can arise by learners stumbling on new information serendipitously or out of curiosity (Sharples et al. 2005). Fourthly, the control over learning does not rest with the teacher in mobile learning, instead it is distributed between user (Sharples et al. 2005). Mobile learning can conflict and complement formal learning, has ethical issues related to the learners' privacy, due to parents and teachers being able to monitor all of students’ activity (Sharples et al. 2005). Sharples et al. argue that while many of these are true 
for all types of informal learning "the distinctive aspects of mobile learning are its mobility, the informally arranged and distributed participants, and the interaction between learning and portable technology" (Sharples et al. 2005, 4). Therefore, they feel that mobile learning is significantly different than other types of learning (Sharples et al. 2005). Since, social media usage, is used in the same mobile manner as mobile learning (with most people using primarily mobile phones for access to social media, interchanging access with less mobile devices), the informal learning through social media, is in fact mobile learning and we will use the same framework that Sharples’ et al. uses to describe their learning.

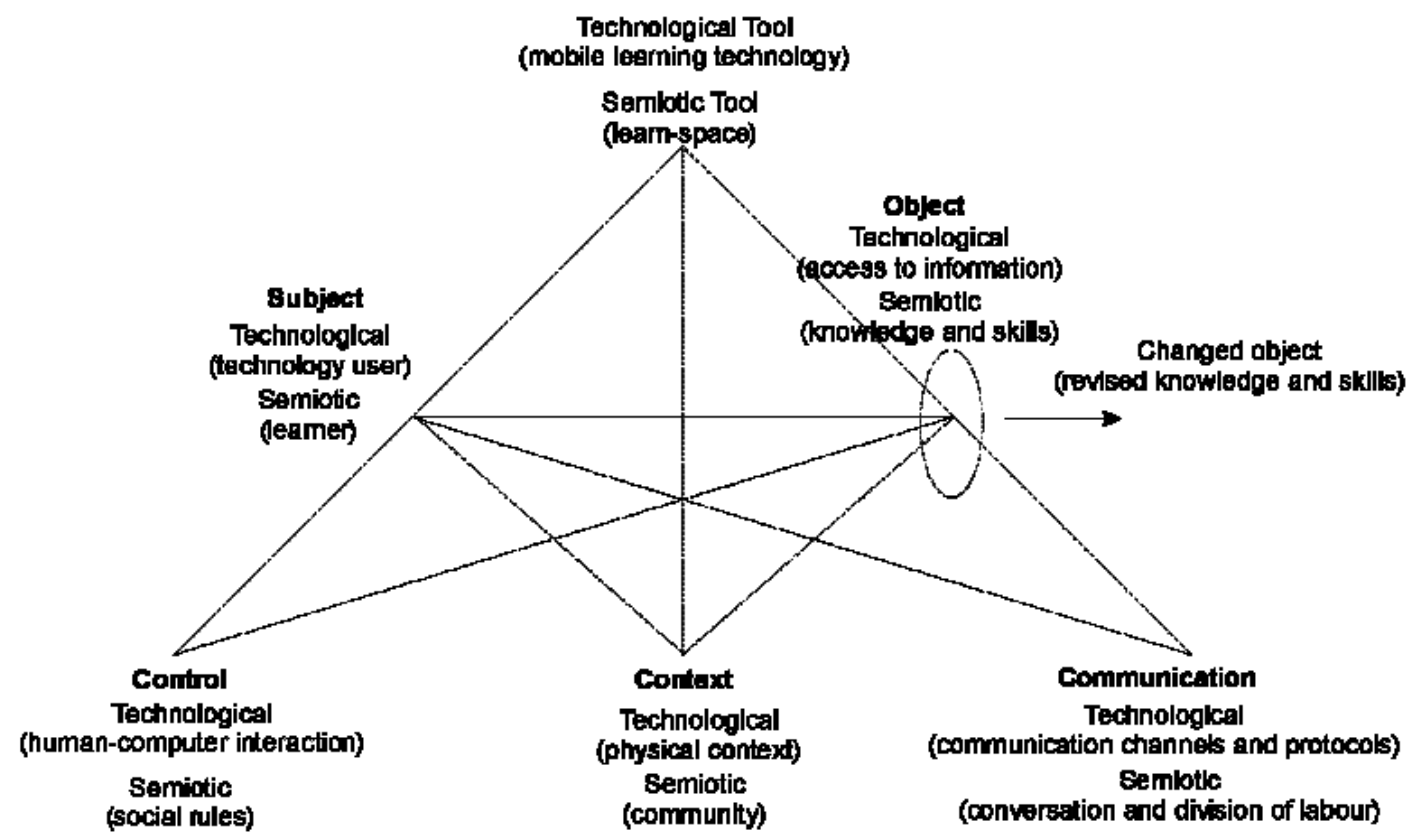

Figure 6: A framework for analysing mobile learning (Sharples et al. 2005)

Because they believed that learning through mobile technology was a significantly different process to traditional forms of learning, they thought it was imperative to rework Engeström's 3GAT model (Sharples et al. 2005). They have developed an analysis of learning as a conversation, much like the conversations on social media, “drawing on Dewey’s philosophy of Pragmatic Technology and Pask's Conversation Theory as foundations on which to build an account of the process of coming to know in a world mediated by mobile technology" (Sharples et al. 2005). The reworked activity model therefore separated the technology with semiotics by including separate layers for each in their activity. Figure 6 (Sharples et al. 2005), shows this new model.

Analysing the new model, we can see that the semiotic layer, is the same as Engeström's expansive learning model, however with the introduction of the technological layer, the bottom 
level or the cultural factors of the Engeström's triangle need to be adapted to account for both the technological and the semiotic (Sharples et al. 2005). Sharples et al. introduce three new concepts which describes the dialectical relationship between the technology and learning (Sharples et al. 2005). The concept of control was introduced to discuss the interaction between the learners and the technology, the rights and permissions that are afforded by the technology, the pace and style of the interaction and the social rules that governs the community that is interacting online (Sharples et al. 2005). Context was introduced to explain the physical interaction and access with computers and the community that is accessed through and around the use of this technology (Sharples et al. 2005). Lastly, communication describes the various forms and media through which learners can share ideas through technology and the interaction between these forms of communication and the way the conversation space is shared between its various participants (Sharples et al. 2005).

Using the framework provided by Sharples, we have constructed an activity system to describe the use of social media to mediate learning during the RMF protests (Figure 7).

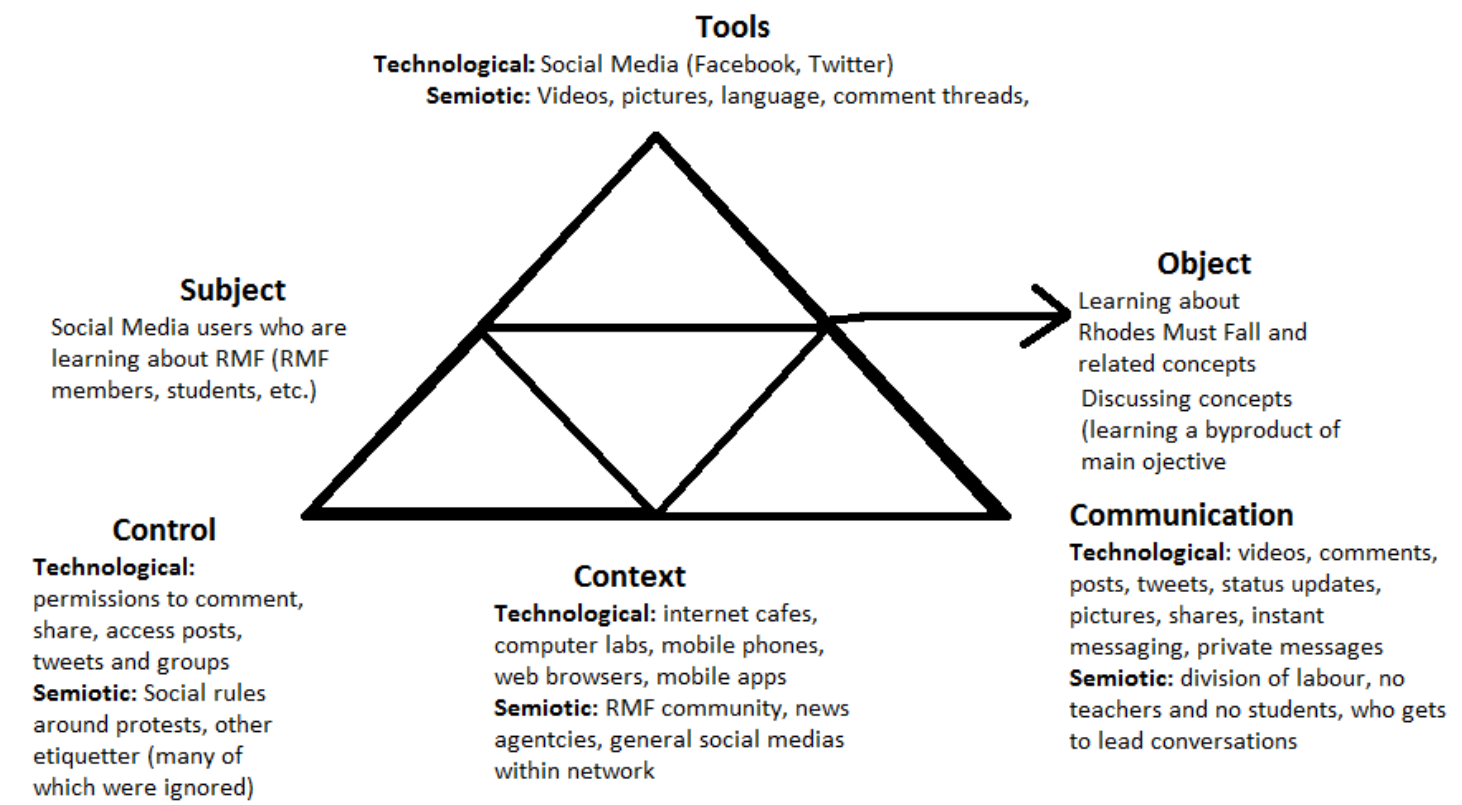

Figure 7: Technology mediated Activity System for Rhodes Must Fall

While all six subcomponents offer us a rich source of insight into social media users' learning about Rhodes Must Fall and its related concepts, in this article due to space constraints, we focus mainly on Social media as a tool and communication.

\section{SOCIAL MEDIA AS A TOOL}

In response to marginalisation of certain population groups at Australian universities, Eijkman 
suggests that that Web 2.0 social media can offer HEIs more discursively inclusive spaces (Eijkman 2009). Eijkman argues that knowledge construction in Web 2.0's spaces are democratic and egalitarian, thus it can make the marginalised epistemologies and discourses more visible (Eijkman 2009). He states that, “Web 2.0’s new mode of socially focused and egalitarian knowledge production provides a powerful window of opportunity to disrupt Western epistemic and discursive hegemony and promote more epistemologically and discursively egalitarian transcultural learning zones” (Eijkman 2009, 240).

Eijkman's description of social media as a decolonising tool has very important implications for our activity system (Eijkman 2009). Firstly, Web 2.0 can play an important role in shifting to a non-foundational approach which is an important precondition for genuine intercultural learning (Eijkman 2009). This can create inclusive transcultural learning zones that enhances the participation of nonmainstream students and allows them to participate as equals (Eijkman 2009). Secondly, the technological shift of universities offers us a new epistemological paradigm. In this paradigm, Web 2.0 acts a method for decentralisation of authority and a freedom to reuse and share content (Eijkman 2009, 240). Thirdly, Web 2.0 offers a transparent space in which students and teachers can interact on a level playing field. Finally, “Web 2.0's socially driven usages incorporate a different epistemic premise; there is an acknowledgement that language, thinking, learning, and literacy practices are rooted in the epistemic patterns of cultural groups, that the perspectives of the marginalised deserve to be heard, and that epistemic negotiations are an essential prerequisite to respectful egalitarian dialogue” (Eijkman 2009, 245).

\section{COMMUNICATION AND DIVISION OF LABOUR WITH SOCIAL MEDIA}

As argued above, social media as a tool can create egalitarian spaces that can lead to decolonised spaces of learning. The effect of this on the division of labour is crucial to understanding this decolonising potential of social media as a mediating learning tool. As Eijkman suggests, Web 2.0 and social media allows for a decentralisation of authority and a freedom to reuse and share content (Eijkman 2009). This also means that users are free to create and produce their own content as well. During the protests we have observed users sharing photos, videos and posts that they have created in order to inform and educate other about the protests. In response to these posts, users also have commented in opposition and support, in refuting and substantiating the various beliefs and opinions in the posts. Through these spaces, meaning, new knowledge and new schemas are being constructed by social media and a greater understanding is gained about the RMF movement and the need to decolonise our universities. However, what is more important is that on social media there is no defined role of teacher and learner and in these 
spaces, the teacher-learner binary is destroyed. Therefore, the curricula, knowledge production and learning is the hands of the individual social media usage and therefore social media provides a space for learning that is decolonised. Students who felt alienated and voiceless can be given a voice by leveraging social media to be heard and those who felt marginalised are now given access to sending and receiving information and are also included in the knowledge production process. We need to study this power of social media to decolonise learning spaces to get a better understanding of how HEI's can leverage social media to empower their students.

\section{RHODES MUST FALL AS A RUNAWAY OBJECT}

While Rhodes Must Fall has made waves locally, it has also made waves internationally affecting universities in the United Kingdom and the United States (Kamanzi 2015; Hlophe 2015). It is evident that the object to decolonise universities is becoming a global object and therefore a runaway object. Analysing RMF movement as runaway object helps us recognise that these interactions on social media do not exist in a vacuum but are shared and retweeted for the world to see and interact on. Therefore, the activity systems that are created through sharing, reading, and posting are intertwined with one another and cannot be separated. What we see is these threads of online learning, informing, and organising activities all being knotworked with threads of protest, political and policy-making activities. It is important to note that the objects of these smaller activities are sub-objects of the greater Rhodes Must Fall runaway object and that their objects influence each other. Understanding this helps us to recognise that no individual's or organisation's social media usage can be studied in isolation, but rather that it is the mycorrhizal activity of both formal and informal institutions, offices and officers that will eventually achieve the goal of decolonising our universities. However, it is evident that social media as a tool has an important role to play in many of these sub-activities and even in mycorrhizae-making and knotworking activities and understanding its role will better leverage a collective effort of equal and inclusive participation to decolonise our universities and provide better learning experience for all students.

\section{CONCLUSION}

Cultural Historical Activity Theory provides us with a rich arsenal of concepts and models to explore the role that social media can play in decolonising South Africa's universities. Social media itself as a tool, provides us with an egalitarian space for transcultural learning which is an important step for understanding the multiple perspectives around decolonising South African universities. Social media destroys the traditional teacher/learner binary, which gives each student/user an equal opportunity to produce knowledge, learn and expose other users and 
learners to new and different epistemologies and experiences that they may not be exposed to without this medium. The ability for multiple epistemologies to exist within the social media learning spaces might give us further insight for how this can be made possible in formal courses at our universities. Universities have been making efforts to decolonise and transform their curricula and teaching practices and further research into social media might provide us valuable insight into how this can be achieved. The students have chosen social media for a reason, it is time that we explore their social media usage more deeply so that we can better understand how to decolonise our universities.

\section{REFERENCES}

Choudry, A. and D. Kapoor. 2010. Learning from the ground up: Global perspectives on social movements and knowledge production. In Learning from the ground up: Global perspectives on social movements and knowledge production, ed. A. C. and D. Kapoor. New York, NY, USA: Palgrave MacMillan.

Eijkman, H. 2008. Towards Web 2.0 enabled postcolonial learning in transcultural higher education. In Readings in education and technology: Proceedings of ICICTE 2007, 625-637. http://www.icicte. org/ICICTE2008Proceedings/eijkman028.pdf

Eijkman, H. 2009. Using Web 2.0 to decolonise transcultural learning zones in higher education. Campus-Wide Information Systems 26(3): 240-255.

Engeström, Y. 2001. Expansive learning at work: Toward an activity theoretical reconceptualization. Journal of Education and Work 14(1): 133-156. http://www.informaworld.com/ openurl?genre=article \&doi=10.1080/13639080020028747\&magic $=$ crossref $\mid$ D404A21C5BB053 405B1A640AFFD44AE3

Engeström, Y. 2006. Development, movement and agency: Breaking away into mycorrhizae activities. Building activity theory in practice: Toward the next ..., 1-46. http://chc.ucsd.edu/mca/ Mail/xmcamail.2008_12.dir/att-0247/Yrjo.dev.pdf

Engeström, Y. 2009. The future of activity theory: A rough draft. In Learning and expanding with activity theory, ed. A. Sannino, H. Daniels and K. D. Gutierrez, 391. Cambridge, UK: Cambridge University Press. http://lchc.ucsd.edu/MCA/Mail/xmcamail.2012_01.dir/pdfHqmCdPgVef.pdf

Gerbaudo, P. 2012. Tweets and the streets: Social media and contemporary activism. $1^{\text {st }}$ Edition. London, UK: Pluto Press.

Hardman, J. 2008. Researching pedagogy: An activity theory approach. Journal of Education 45: 6393.

Hardman, J. 2010.Variation in semiotic mediation across different pedagogical contexts. Education as Change 14(1): 91-106.

Hardman, J. and A. Amory. 2015. Introduction to cultural-historical activity theory and tool mediation. In Activity theory, authentic learning, ed. V. Bozalek et al., 1-21. Oxon, United Kingdom: Routledge.

Hlophe, W. 2015. HLOPHE: Rhodes must fall everywhere. Yale News. http://yaledailynews.com/ blog/2015/04/01/rhodes-must-fall-everywhere/ (Accessed 12 August 2016).

Kamanzi, B. 2015. "Rhodes Must Fall”- Decolonisation symbolism - What is happening at UCT, South Africa? The Postcolonialist. http://postcolonialist.com/civil-discourse/rhodes-must-falldecolonisation-symbolism-happening-uct-south-africa/ (Accessed 12 August 2016).

Kangasoja, J. 2002. Complex design problems: An impetus for learning and knotworking. Keeping Learning Complex: The Proceedings of the Fifth International Conference on the Learning 
Sciences (ICLS), 199-205. http://www.edu.helsinki.fi/activity/publications/files/47/icls 2002_kangasoja.pdf

Lim, M. 2012. Clicks , cabs, and coffee houses : Social media and oppositional movements in Egypt, 2004-2011. Journal of Communication 62: 231-248. http://onlinelibrary.wiley.com.ezproxy. uct.ac.za/doi/10.1111/j.1460-2466.2012.01628.x/epdf

Maireder, A. and C. Schwarzenegger. 2012. A MOVEMENT OF CONNECTED INDIVIDUALS. Information, Communication and Society 15(2): 171-195. http://dx.doi.org/10.1080/ 1369118X.2011.589908

Masondo, S. 2015. Rhodes Must Fall campaign gains momentum at UCT. City Press. http://www.news 24.com/SouthAfrica/News/Rhodes-Must-Fall-campaign-gains-momentum-at-UCT-20150323

McMichael, H. 1999. An activity based perspective for information systems research. In Proceedings of 10th Australasian Conference on Information Systems, 610-621. http://www.citeseerx. ist.psu.edu/viewdoc/download?doi=10.1.11.2988

Sharples, M., J. Taylor and G. Vavoula. 2005. Towards a theory of mobile learning. In Proceedings of mLearn, 1-9. The Open University, UK: University of Birmingham, UK.

Spinuzzi, C. 2011. Losing by expanding: Corralling the runaway object. Journal of Business and Technical Communication 25(4): 449-486.

Spinuzzi, C. 2014. How nonemployer firms stage-manage ad hoc collaboration: An activity theory analysis. Technical Communication Quarterly 23(2): 88-114. http://www.tandfonline.com/ doi/abs/10.1080/10572252.2013.797334

Valenzuela, S. 2013. Unpacking the use of social media for protest behavior: The roles of information, opinion expression, and activism. American Behavioral Scientist 57(7): 920-942. http://abs.sage pub.com/cgi/doi/10.1177/0002764213479375

Verbaan, A. 2015. UCT student in poo protest. Cape Times. http://www.iol.co.za/capetimes/uct-studentin-poo-protest-1829512 (Accessed 12 August 2016). 